\title{
When Neuropediatrics Meets Odontology
}

Ataxia, delayed dentition and hypomyelination: a novel leukoencephalopathy; what an extraordinary phenotype is described in the paper by Wolf et al. [30] in this journal issue.

It is rare indeed nowadays to see a new disease described and even more noteworthy that the precise delineation of this syndrome has been recognised through a combination of symptoms gathered by multidisciplinary international teams from medical genetics to neurology, paediatrics and paediatric dentistry.

The authors suggest that, "in every child with early onset ataxia, teeth should be inspected. Vice versa in a child with delayed dentition and lacking incisors, neurological abnormalities should be looked for...".

Teeth abnormalities are indeed excellent dysmorphic markers, providing visible evidence, through their unchanging mineralised state, of earlier developmental abnormalities, and giving warning signs that may provide sign-posts in syndrome diagnosis.

Dental abnormalities may be classified into five main groups; number (missing [3] or supernumerary teeth), shape (conical, tapered...), size (small or microdont teeth, large or macrodont teeth), hard tissue structure (like amelogenesis imperfecta for enamel defects $[10,31]$ or dentinogenesis imperfecta or dentin dysplasia for dentin defects [20]), and root formation, (including eruption and resorption).

These anomalies may in turn be genetic or environmental, as the results of teratogenic assaults during the stages of formation or mineralisation of tooth germs [1,2]. Such abnormalities are indeed frequently noted in the clinical synopsis of many syndromes, but often with little or no attempt to link them to the pathogenesis of the condition seen.

A few examples with associated neurological symptoms have now been recognised. Congenitally missing permanent teeth are a common finding in Rieger syndrome, with a very peculiar pattern of presentation (the permanent maxillary incisors are absent) that is more important to recognise than the overall number of absent elements. A recent paper [18] has shown that a novel Arg5Trp missense mutation in the PITX2 homeodomain, responsible for the Rieger phenotype in the described family, was further associated with brain abnormalities.

Re:Wolf NI, Harting I, Innes AM, Patzer S, Zeitler P, Schneider A, Wolff A, Baier K, Zschocke J, Ebinger F, Boltshauser E, Rating D: Ataxia, Delayed Dentition and Hypomyelination: A Novel Leukoencephalopathy
The development of a single, upper, permanent central incisor is a discrete sign for holoprosencephaly [15]. Macrodont large central incisors are a diagnostic clue in KBG syndrome [6]. Talon cusps, an accessory cusp-like structure projecting from the palatal surface of upper and lower anterior teeth are seen in $70 \%$ of patients with Rubinstein-Taybi syndrome [5].

Amelogenesis imperfecta may be associated with neurological degeneration in Kohlschütter syndrome $[11,14]$. This enamel pathology has also been described in association with cone-rod dystrophy [22]. Examples are numerous and the London Neurogenetics database created by $R$. Winter and M. Baraitser describes 447 syndromes with dental anomalies [12].

The Master and Father of OdontoGenetics, the late Professor Robert J. Gorlin [17], author of the famous book "Syndromes of the Head and Neck" described many syndromes with neurological disorders, craniofacial and dental abnormalities [13]. He started his professional career with dentistry and became a world famous geneticist and oral pathologist. He recognised the tooth as an appropriate starting point for dysmorphology and genetics.

The tooth is indeed a good model in developmental biology.

Dental development encompasses a very large timeframe, from initial neural crest cell formation and migration around day 22 in human embryogenesis to the completion of root formation of the third molars or wisdom teeth around 20-25 years of age. Odontogenesis results in the formation of specific crown and root morphogenesis for each type of teeth (incisors, canines, premolars, molars). It is driven by epithelio-mesenchymal interactions between a localised area of the oral ectoderm of the first branchial arch (from which derive the enamel organ, inner dental epithelium and ameloblasts cells) and ectomesenchymal cells originating from the cephalic neural crest [8] extending to the formation of odontoblasts, dental pulp cells, and of the specialised tissues that both surround and support the teeth, the cementum and periodontium. Tooth development is an extraordinarily complex process, which progresses through different stages from the initial dental lamina, through bud, cap and bell stages to terminal cytodifferentiations of odontoblasts and ameloblasts - the post-mitotic cells that synthesise dentin and enamel matrix proteins, respectively.

Odontogenesis is under strict genetic control and more than 300 genes involved in these developmental processes have already been identified 
(see http://bite-it.helsinki.fi) [24]. They encode for proteins belonging to various interacting molecular signalling pathways (Tgfß, Fgfs, Shh, Wnt) and for transcription factors.

Each dental anomaly $[23,26]$ may be related to errors in specific developmental issues such as the embryological origin of dental cells, patterning of the dentition [28], placode formation [25], crown and root morphogenesis [19], signalling centres, i.e., the enamel knots controlling cusps formation $[9,27]$, histogenesis, terminal cytodifferentiations of odontoblasts this peculiar ciliated cell type [21] and ameloblasts, dentin and enamel matrices synthesis $[4,7]$, mineralisation, bone remodelling and eruption $[16,29]$.

The resulting appearance of the teeth therefore gives clear, if cryptic, evidence of the processes affected during development. It is therefore important to recognise, characterise and record precisely dental anomalies and phenotypes so that they may be integrated within the familial, medical and dental histories of the patient. Such detailed recording will reveal developmental origins and go some way towards providing additional clues for understanding underlying aetiopathogenic mechanisms and unravelling a syndrome diagnosis.

The D[4]/phenodent database (Diagnosing Dental Defect Database (www.phenodent.org) proposes a systematic assessment method of dental phenotypes encountered in genetic diseases. The specialist dentist expert who is able to recognise orodental anomalies is an indispensable partner of the multidisciplinary team working with a particular patient.

In Europe some of these professionals belong to networks linking clinical diagnosis centres and research laboratories (European Cooperation in the field of Scientific and Technical Research, COST Action B23 Oro-Facial Development and Regeneration; In France, INSERM (French Medical Research Agency) "Réseau de Recherche Clinique et Réseau de Recherche en Santé des populations 2003"; GIS maladies rares, Odontogenetics network; French National Rare Disease Plan 2004-2008 certificating in 2006 a Reference Centre for Orodental Manifestations of Rare Diseases in Strasbourg).

A precise and detailed phenotype is of course the key to accurate genotype phenotype correlation and the discovery of new genes. There is every reason for us to enhance links between Neuropediatrics and Odontology and find in the smiles of our patients, clues to their care.

\section{A. Bloch-Zupan}

\section{Affiliation}

Faculté de Chirurgie Dentaire, Université Louis Pasteur; Centre de référence des manifestations odontologiques des maladies rares, Service de Soins Bucco-Dentaires, Centre Hospitalier Universitaire, Strasbourg, France

IGBMC (Institut de Génétique et de Biologie Moléculaire et Cellulaire), Département Génétique et Physiologie; Inserm, U596; CNRS, UMR7104, Illkirch, France

Eastman Dental Institute, Institute of Child Health, University College London, London, UK

\section{References}

1 Alaluusua S. Amoxicillin may be a cause of enamel hypomineralization. Duodecim 2006; 122: 491-492

2 Alaluusua S, Lukinmaa PL. Developmental dental toxicity of dioxin and related compounds - a review. Int Dent J 2006; 56: 323-331
3 Arte S, Pirinen S. Hypodontia. Orphanet encyclopedia 2003. http:// www.orpha.net/data/patho/GB/uk-hypodontia.pdf:update 2004

4 Bartlett JD, Ganss B, Goldberg M, Moradian-Oldak J, Paine ML, Snead ML et al. Protein-protein interactions of the developing enamel matrix. Curr Top Dev Biol 2006; 74: 57-115

5 Bloch-Zupan A, Stachtou J, Emmanouil D, Arveiler B, Griffiths D, Lacombe D. Oro-dental features as useful diagnostic tool in Rubinstein-Taybi syndrome. Am J Med Genet A 2007; 143: 570-573

6 Brancati F, Sarkozy A, Dallapiccola B. KBG syndrome. Orphanet J Rare Dis 2006; 1: 50

7 Butler WT, Brunn JC, Qin C. Dentin extracellular matrix (ECM) proteins: comparison to bone ECM and contribution to dynamics of dentinogenesis. Connect Tissue Res 2003; 44 (Suppl 1):171-178

8 Cobourne MT, Mitsiadis T. Neural crest cells and patterning of the mammalian dentition. J Exp Zoolog B Mol Dev Evol 2006; 306: 251-260

9 Courtney JM, Blackburn J, Sharpe PT. The ectodysplasin and NFkappaB signalling pathways in odontogenesis. Arch Oral Biol 2005; 50: 159-163

10 Crawford PJ, Aldred MJ, Bloch-Zupan A. Amelogenesis imperfecta. Orphanet J Rare Dis 2007; 2: 17

11 Donnai D, Tomlin PI, Winter RM. Kohlschutter syndrome in siblings. Clin Dysmorphol 2005; 14: 123-126

12 Fryns JP, Ravel TJ de. London Dysmorphology Database, London Neurogenetics Database and Dysmorphology Photo Library on CD-ROM [Version 3] 2001. R. M. Winter, M. Baraitser Oxford University Press, Hum Genet 2002; 111: 113

13 Gorlin RJ, Cohen MM, Hennekam JRCM. Syndromes of the head and neck 4th edn. Oxford: University Press, 2001

14 Haberlandt E, Svejda C, Felber S, Baumgartner S, Gunther B, Utermann G et al. Yellow teeth, seizures, and mental retardation: a less severe case of Kohlschutter-Tonz syndrome. Am J Med Genet A 2006; 140: 281-283

15 Hall RK. Solitary median maxillary central incisor (SMMCI) syndrome. Orphanet J Rare Dis 2006; 1: 12

16 Helfrich $\mathrm{MH}$. Osteoclast diseases and dental abnormalities. Arch Oral Biol 2005; 50: 115-122

17 Hennekam RC, Robert J. Gorlin (1923-2006): teacher, colleague, and friend. Am J Med Genet A 2006; 140: 2514-2515

18 Idrees F, Bloch-Zupan A, Free SL, Vaideanu D, Thompson PJ, Ashley P et al. A novel homeobox mutation in the PITX2 gene in a family with Axenfeld-Rieger syndrome associated with brain, ocular, and dental phenotypes. Am J Med Genet B Neuropsychiatr Genet 2006; 141: 184-191

19 Luan X, Ito Y, Diekwisch TG. Evolution and development of Hertwig's epithelial root sheath. Dev Dyn 2006; 235: 1167-1180

20 MacDougall M, Dong J, Acevedo AC. Molecular basis of human dentin diseases. Am J Med Genet A 2006; 140: 2536-2546

21 Magloire H, Couble ML, Romeas A, Bleicher F. Odontoblast primary cilia: facts and hypotheses. Cell Biol Int 2004; 28: 93-99

22 Michaelides M, Bloch-Zupan A, Holder GE, Hunt DM, Moore AT. An autosomal recessive cone-rod dystrophy associated with amelogenesis imperfecta. J Med Genet 2004; 41: 468-473

23 Miletich I, Sharpe PT. Normal and abnormal dental development. Hum Mol Genet 2003; 12 (Spec No 1):69-73

24 Nieminen P, Pekkanen M, Aberg T, Thesleff I. A graphical WWW-database on gene expression in tooth. Eur J Oral Sci 1998; 106 (Suppl 1): 7-11

25 Pispa J, Thesleff I. Mechanisms of ectodermal organogenesis. Dev Biol 2003; 262: 195-205

26 Thesleff I. The genetic basis of tooth development and dental defects. Am J Med Genet A 2006; 140: 2530-2535

27 Thesleff I, Jernvall J. The enamel knot: a putative signaling center regulating tooth development. Cold Spring Harb Symp Quant Biol 1997; 62: 257-267

28 Tucker A, Sharpe P. The cutting-edge of mammalian development; how the embryo makes teeth. Nat Rev Genet 2004; 5: 499-508

29 Wise GE. The biology of tooth eruption. J Dent Res 1998; 77: 1576-1579

30 Wolf NI, Harting I, Innes AM, Patzer S, Zeitler P, Schneider A et al. Ataxia, delayed dentition and hypomyelination: a novel leukoencephalopathy. Neuropediatrics 2007; 38: 64-70

31 Wright JT. The molecular etiologies and associated phenotypes of amelogenesis imperfecta. Am J Med Genet A 2006; 140: 2547-2555 